www.jmscr.igmpublication.org

Impact Factor 5.244

Index Copernicus Value: 5.88

ISSN (e)-2347-176x ISSN (p) 2455-0450

crossref DOI:_http://dx.doi.org/10.18535/jmscr/v4i3.03

Journal Of Medical Science And Clinical Research

IGM Publication

An official Publication of IGM Publication

\title{
Role Of Sonological Fetal Cerebellar Measurement In Gestational Age Determination
}

\author{
Authors \\ Dr Sandeep $S^{1}$, Dr Parthasarathi $A^{2}$ \\ ${ }^{1}$ Assistant Professor, Dept of Radiodiagnosis, St. John's Medical College, Bangalore \\ ${ }^{2}$ Assistant Professor, Dept of Radiodiagnosis, Rajarajeswari Medical College and Hospital, Bangalore \\ Department Of Radio-Diagnosis, St. John's Medical College, Sarjapur Road, Bangalore, Karnataka \\ India. Pin 560034 \\ Corresponding Author \\ Dr Sandeep S \\ Assistant Professor, Dept of Radiodiagnosis, St. John's Medical College Sarjapur Road, \\ Bangalore, Karnataka, India Pin 560034 \\ Email-dr.sandeep.mdrd@gmail.com, Phone :+919845089594
}

\section{ABSTRACT:}

Sonographic measurement of fetal biparietal diameter is a well accepted predictor of gestational age. However there is a high variability in the calculated gestational age which increases as pregnancy progresses. The estimation of gestational age from individual parameters like the HC, AC, and FL also shows a similar variability. Using all the above parameters this variability can be reduced by $25 \%$ to $30 \%$. There are conditions like oligohydromnios, multiple gestation, breech presentation and intrauterine growth restriction (IUGR) that can alter the shape of the fetal skull which in turn can affect the BPD and increase the variability. The present study is being undertaken to measure the transverse cerebellar diameter (TCD) to validate it as an additional morphological measurement of fetal growth with less variability. The cerebellum and posterior fossa are aligned perpendicular to the plane of maximum extrinsic compression. Hence, they are able to withstand deformation by extrinsic pressure than the parietal bones and can be a more accurate parameter for the determination of gestational age.

KEYWORDS: Transverse Cerebellar Diameter, Biparietal Diameter, Head Circumference, Abdominal Circumference, Femur Length, Intra-uterine Growth Restriction, Pre-Natal Diagnostic Techniques, Amniotic Fluid Index, Last Menstrual Period

\section{INTRODUCTION}

Obstetric sonography plays an important role in the accurate determination of intrauterine gestational age. Knowledge of gestational age is important in following ways ${ }^{1}$ : i) To anticipate normal spontaneous delivery or to plan elective delivery within the time frame of a term pregnancy (38 weeks to 42 weeks). ii) To consider invasive procedures such as chorionic villus sampling, genetic amniocentesis and in interpretation of biochemical tests such as maternal serum alpha-fetoprotein screening. iii) To evaluate the fetal growth. iv) Gestational age influences the management decision if the fetus is 
diagnosed with an anomaly. Hence all important clinical decisions are influenced by the gestational age.

Before the advent of sonography, gestational age was calculated with the help ofi) menstrual history ii) physical examination of the uterine size. iii) $X$ ray estimation of gestation age ossification center development iv) Maternal sensation of fetal movement v) Initial detection of fetal heart tones. In limited cases, basal body temperature and leutinizing hormone (LH) surge indicator are also used for estimating gestational age with accuracy of +/- 6 days. But these parameters have high variability. ${ }^{1,2}$.

The last two decades have seen a tremendous progress in application of ultrasound as a diagnostic modality revolutionizing the management towards better care. This is particularly due to its non-invasive, non-ionizing nature, easy availability and cost effectiveness leading to wider acceptability. The exemplary safety record of diagnostic ultrasound is probably an important reason that it has become so widely used. ${ }^{3}$ Ultrasound is safe for the patient, the fetus and the sonologist. There is no reported risk of ionizing radiation as in radiography, ${ }^{4}$ or any other known biological or embryotoxic effect. It does not require any injections as sometimes needed in imaging studies. ${ }^{5} \mathrm{~A}$ single or repeated intrauterine exposure to ultrasound, early or late in pregnancy does not carry the known risk of development of lymphatic or myeloid childhood leukemia, ${ }^{6}$ as with X-rays. It is not associated with any harm to early fetal life, growth and vision or hearing during childhood. ${ }^{7}$ Similarly no adverse effects have been observed on neurological development and subsequent school performance of the children. ${ }^{8}$

Sonographic measurement of fetal biparietal diameter is a well accepted predictor of gestational age. ${ }^{9,10}$ However there is a high variability in the calculated gestational age which increases as pregnancy progresses with maximum difference approximating 3.6 weeks in the third trimester. $^{11,12}$ The estimation of gestational age from individual parameters like the $\mathrm{HC}, \mathrm{AC}$, and
FL also shows a similar variability. Using all the above parameters this variability can be reduced by $25 \%$ to $30 \%{ }^{13}$ There are conditions like oligohydromnios, multiple gestation, breech presentation and intrauterine growth restriction (IUGR) that can alter the shape of the fetal skull which in turn can affect the BPD and increase the variability. ${ }^{14}$ Multiple gestations and IUGR can also affect the abdominal and femoral measurement. The present study is being undertaken to measure the transverse cerebellar diameter (TCD) to validate it as an additional morphological measurement of fetal growth with less variability. The cerebellum and posterior fossa are aligned perpendicular to the plane of maximum extrinsic compression. Hence, they are able to withstand deformation by extrinsic pressure than the parietal bones ${ }^{14}$ and can be a more accurate parameter for the determination of gestational age.

\section{OBJECTIVE OF THE STUDY}

1. To perform obstetric ultrasonography in healthy women with uncomplicated pregnancy between the $28^{\text {th }}$ week of gestation and term to determine a correlation between the transverse cerebellar diameter and the gestational age as determined by the last menstrual period and other Sonographic parameters like biparietal diameter, head circumference, abdominal circumference and femur length.

2. To derive nomogram for estimating the gestational age of the fetus from ultrasonographically measured transverse cerebellar diameter.

\section{METHODOLOGY}

A prospective study was done in 100 healthy women with uncomplicated pregnancy between the $28^{\text {th }}$ week of gestation and term, referred from routine antenatal clinic in outpatient and in-patient sections of Obstetrics and Gynecology.

This study is undertaken to determine a correlation between the transverse cerebellar 
diameter and the gestational age as determined by the last menstrual period and other sonographic parameters like biparietal diameter, head circumference, abdominal circumference and femur length.

\section{INCLUSION CRITERIA}

Healthy women with uncomplicated pregnancy between the $28^{\text {th }}$ week of gestation and term.

\section{EXCLUSION CRITERIA}

1. Unknown or inaccurate date of last menstrual period.

2. Irregular menstrual cycles.

3. Oligohydramnios.

4. Polyhydramnios.

5. Diabetic mother.

6. Pregnancy induced hypertension.

7. Pre eclampsia.

8. Dolichocephalic skull.

9. Multiple gestation.

10. Fetal chromosomal abnormalities.

11. Fetal anomalies.

12. Intrauterine growth restriction.

13. Any other known maternal and fetal abnormality.

\section{FETAL BIOMETRY}

Fetal biometry is a methodology devoted to the measurement of the several parts of fetal anatomy and their growth. ${ }^{15}$ Fetal growth is defined as the time dependent changes in body dimensions that occur throughout the pregnancy.

\section{FIRST TRIMESTER DATING:}

Sonographic milestones of early pregnancy and measurement of the embryo once it can be visualized by ultrasound allow highly accurate dating from five weeks gestation until the end of first trimester. ${ }^{16}$

\section{GESTATION SAC:}

The gestation sac is demonstrated as a circular echo free area enclosed by a reflective ring within the uterine cavity. It is visible from 5 to 6 weeks post menstrual age by transabdominal scanning or week earlier using transvaginal scanning. ${ }^{17}$ Mean sac diameter (MSD) provides an estimation of gestational age in a normally developing pregnancy. ${ }^{1} \mathrm{MSD}$ is the average internal diameter of the gestational sac, calculated as the mean of the AP, transverse and longitudinal diameter. MSD increases about $1 \mathrm{~mm}$ per day in early gestation. $^{18-21}$

\section{CROWN RUMP LENGTH (CRL):}

The CRL is the length of the embryo or fetus from the top of its head to the bottom of its torso. ${ }^{15}$ It is measured as the longest dimension of the embryo, excluding the yolk sac and the extremities. ${ }^{15}$

\section{SECOND AND THIRD TRIMESTER DATING:}

Many sonographic parameters have been proposed for estimating gestational age in the second and third trimesters. These include several fetal measurements : BPD, HC, AC, FL, length of other long bones, binocular distance and combinations of two or more fetal measurements.

\section{BIPARIETAL DIAMETER:}

The transition between first and second trimesters (13 to 14 weeks) is also the appropriate time to make the transition from CRL to BPD, HC, AC and FL. ${ }^{1}$ The rule for measuring BPD is as follows 1 :

I. Plane of section through the third ventricle and thalami.

II. Calvaria are smooth and symmetric bilaterally.

III. The cursors are positioned in one of the three following ways.

1. Outer edge of near calvarial wall to inner edge of far calvarial wall.

2. Inner edge of near calvarial wall to outer edge of far calvarial wall.

3. middle of near calvarial wall to middle of far calvarial wall.

The occipitofrontal diameter (OFD) is obtained from the same plane as the BPD and is measured from mid skull to mid skull along the long axis of the fetal head. ${ }^{16}$ 


\section{HEAD CIRCUMFERENCE:}

Head circumference is one of the most reliable individual parameters for estimation of gestational age. ${ }^{1}$ This is due to its shade independence. ${ }^{1}$ The rule for measuring the $\mathrm{HC}$ are as follows ${ }^{1}$ :

1. Plane of section through the third ventricle and thalami.

2. Cavum septipellucidi must be visible in the anterior portion of the brain and the tentorial hiatus must be visible in the posterior portion of the brain

3. Cursors are positioned at the outer edge of the near calvarial wall and the outer edge of the far calvarial wall.

\section{ABDOMINAL CIRCUMFERENCE:}

The fetal abdominal circumference is the length of the outer perimeter of the fetal abdomen. ${ }^{16}$

The rule of measurement of the fetal AC are as follows ${ }^{1}$ :

1. The cephalocaudal plane where the right and left portal veins are continuous with one another. This is the plane at which the transverse diameter of the liver is the greatest. The fetal stomach is at the same level, which is slightly caudad to the fetal heart and cephalad to the kidneys.

2. Symmetric appearance of the lower ribs.

3. The shortest length of the umbilical segment of the left portal vein should be depicted.

\section{FEMUR LENGTH:}

The length of the diaphysis of the fetal femur is often used for gestational age prediction. ${ }^{22,23,24}$

The rules for measurement of the femur are as follows ${ }^{1}$ :

1. Align the transducer to the long axis of the diaphysis.

2. Plane should show both the cartilaginous femoral head and distal condyle.

3. Place the measurement cursors at the junction of the cartilage and bone. The thin bright reflection of the cartilaginous epiphysis should not be included.
TRANSVERSE CEREBELLAR DIAMETER:

The normal fetal TCD increase with advancing gestational age and exhibit a more than two fold increase in size during the second half of pregnancy. $^{25}$

Normal sonographic anatomy of the developing cerebellum can be misinterpreted for pathological conditions. $^{26,27}$ A study on 19 normal pregnant patients by Catherine J Babcook et al., in 1995, imaged by both sonography and MR imaging. By 13-14 weeks, both sonography and MR imaging demonstrated vermis between the hemispheres rostrally, but the caudal vermis was undeveloped. Although visualized on MR imaging, the caudal fourth ventricular roof was not yet appreciated on sonogram, giving the false impression of communication between the fourth ventricle and the cisterna magna. Separation of these CSF spaces was not appreciated at all levels sonographically until 16 weeks. So caution is warranted in making an early diagnosis of fetal cerebellar dysgenesis. ${ }^{26}$ Open vermis is seen in 56 $\%$ of fetus at 14 weeks gestation, decreasing to $23 \%$ at 15 weeks and $6 \%$ at 17 weeks. So the prenatal diagnosis of Dandy walker variant should not be made before 18 weeks gestation because the development of cerebellar vermis may be incomplete at that time. ${ }^{27}$

A study in 2006 by Toshiyuki Hataet al showed that a curvilinear relationship was found between gestational age and cerebellar volume, and normal ranges of cerebellar volume measurements for estimating the growth of the fetal cerebellum during normal pregnancy were generated. ${ }^{28}$

Sonographic transverse cerebellar diameter is not affected by the alteration in the shape of the fetal skull which affects the biparietal diameter and increase the variability. ${ }^{29-31}$ TCD correlates well with gestational age and is more useful indicator of the accurate gestational age in case of dolichocephaly or brachycephaly and facilitate antenatal detection of congenital disorders. ${ }^{30}$

Difference in actual gestational age and gestational age predicted by TCD is 0-4 days for 17-21 weeks, 0-2 days for 22-28 weeks, > 5 days for 29-36 weeks and 9 days for 37 weeks. ${ }^{32}$ Fetal 


\section{JMSCR Vol||04||Issue||03||Page 9599-9613||March}

TCD correlates well with the clinical gestational age in third trimester also. ${ }^{32,33}$

The fetal TCD / AC ratio is a gestational age independent method of assessing fetal growth. ${ }^{33-37}$ In normal pregnant women the TCD / $\mathrm{AC}$ ratio was fairly constant with the mean of $13.68+/-$ 0.96 irrespective of gestational age. ${ }^{33,35,37}$ A value exceeding $2 \mathrm{SD}$ of the mean was significantly associated with birth of a small for gestational age infants but not useful for identifying large for gestational age infant. ${ }^{35}$

The fetal TCD is not independent of the ethnic origin of the patient. ${ }^{38,39}$ A study in 2001 on 153 normal pregnant women on Thai population concludes that growth rate of TCD was slightly less than that of a western study after 28 weeks of gestation. $^{39}$

A study by Jose Araujo Holanda-Filho et al (2010) concluded that TCD fetal ultrasound as a predictive biometric parameter of gestational age is independent of fetal gender in last two trimesters of a pregnancy. ${ }^{40}$

The fetal TCD is useful for prediction of gestational age at the extremes of fetal growth. ${ }^{41-}$
${ }^{43}$ There is relative preservation of normal cerebellar growth in growth restricted fetuses and a similar rate of growth in singleton and multifetal gestation. In most of growth restricted fetuses, except for TCD all other biometric parameters will be $<10^{\text {th }}$ percentile. $^{41}$ The difference between actual and predicted gestational age based on TCD in IUGR fetus is within 3 days in $97.5 \%$ in the second trimester and $93.3 \%$ in the third trimester. In large for date fetus the difference between actual and predicted gestational age based on TCD is within 3 days was $100 \%$ in both second and third trimesters. ${ }^{42}$

Chavez et al (2006) validated TCD as an accurate gestational age predictor in twin pregnancies too. In their study, high concordance was found between actual and predicted twin TCD measurements based on previously established singleton TCD nomogram. Between 24 and 30 weeks, the predicted mean GA was within 3 days and at 32 weeks or more, the predicted mean GA was within 5 days of the actual GA. ${ }^{44}$

TABLE NO. 1 PREDICTED GESTATIONAL AGE FOR TCD OF 14 TO $56 \mathrm{MM}^{45}$

\begin{tabular}{llll}
\hline $\begin{array}{l}\text { Cerebellum } \\
(\mathbf{m m})\end{array}$ & $\begin{array}{l}\text { Gestational Age } \\
(\mathbf{w k})\end{array}$ & $\begin{array}{l}\text { Cerebellum } \\
(\mathbf{m m})\end{array}$ & $\begin{array}{l}\text { Gestational Age } \\
(\mathbf{w k})\end{array}$ \\
\hline $\mathbf{1 4}$ & 15.2 & 35 & 29.4 \\
\hline $\mathbf{1 5}$ & 15.8 & 36 & 30.0 \\
$\mathbf{1 6}$ & 16.5 & 37 & 30.6 \\
$\mathbf{1 7}$ & 17.2 & 38 & 31.2 \\
\hline $\mathbf{1 8}$ & 17.9 & 39 & 31.8 \\
\hline $\mathbf{1 9}$ & 18.6 & 40 & 32.3 \\
\hline $\mathbf{2 0}$ & 19.3 & 41 & 32.8 \\
\hline $\mathbf{2 1}$ & 20.0 & 42 & 33.4 \\
\hline $\mathbf{2 2}$ & 20.7 & 43 & 33.9 \\
\hline $\mathbf{2 3}$ & 21.4 & 44 & 34.4 \\
\hline $\mathbf{2 4}$ & 22.1 & 45 & 34.8 \\
\hline $\mathbf{2 5}$ & 22.8 & 46 & 35.3 \\
\hline
\end{tabular}




\begin{tabular}{llll}
\hline $\mathbf{2 6}$ & 23.5 & 47 & 35.7 \\
$\mathbf{2 7}$ & 24.2 & 48 & 36.1 \\
$\mathbf{2 8}$ & 24.9 & 49 & 36.5 \\
\hline $\mathbf{2 9}$ & 25.5 & 50 & 36.8 \\
$\mathbf{3 0}$ & 26.2 & 51 & 37.2 \\
\hline $\mathbf{3 1}$ & 26.9 & 52 & 37.5 \\
$\mathbf{3 2}$ & 27.5 & 54 & 38.0 \\
\hline $\mathbf{3 3}$ & 28.1 & 55 & 38.3 \\
\hline $\mathbf{3 4}$ & 28.8 & 56 & 38.5 \\
\hline
\end{tabular}

Hill, L. M., Guzick D. and Fries J.,(1990). Transverse cerebellar diameter as a predictor of menstrual age, ObstetGynecol, 75, $983 .^{45}$

\section{OBSERVATION AND RESULTS:}

GRAPH NO. 1 AGE DISTRIBUTION:

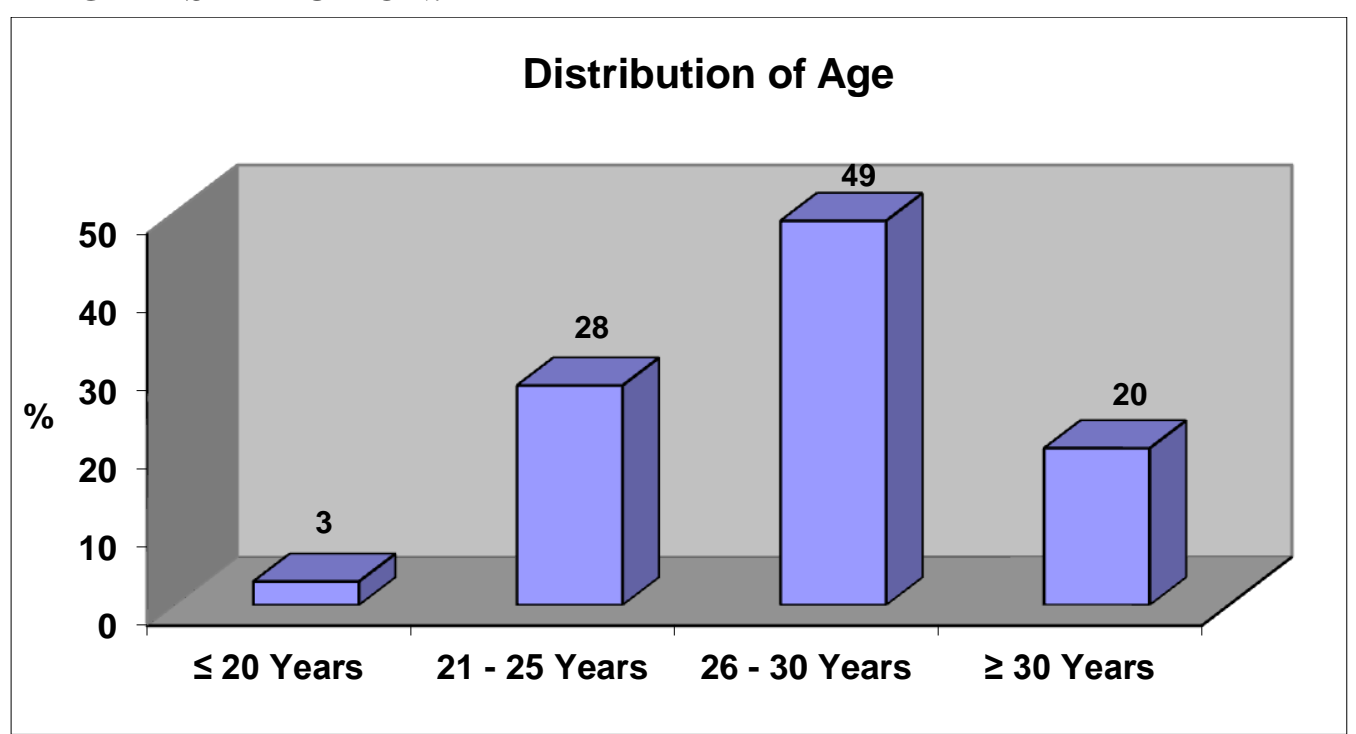

The age of 100 patients included in the study was in the range of 20 to 35 years with the mean age of 27.38 years. Out of these 100 patients included in the study, 3 were in the age group of $<20$ years, 28 were in the age group of 21-25 years, 49 were in the age group of 26-30 years and 20 were in the age group of $>30$ years.

TABLE NO. 2 AGE DISTRIBUTION:

\begin{tabular}{|l|l|}
\hline Age Distribution & \\
\hline Minimum & 20 \\
\hline Maximum & 35 \\
\hline Mean & 27.38 \\
\hline Standard Deviation & 3.558 \\
\hline Median & 27.0 \\
\hline $\mathbf{N}$ & 100 \\
\hline
\end{tabular}


GRAPH NO.2- GRAVIDA DISTRIBUTION:

\section{Gravida Distribution}

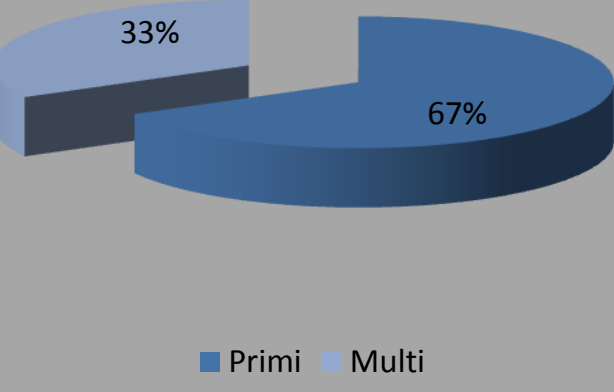

GRAPH NO.3 MULTIGRAVIDA DISTRIBUTION:

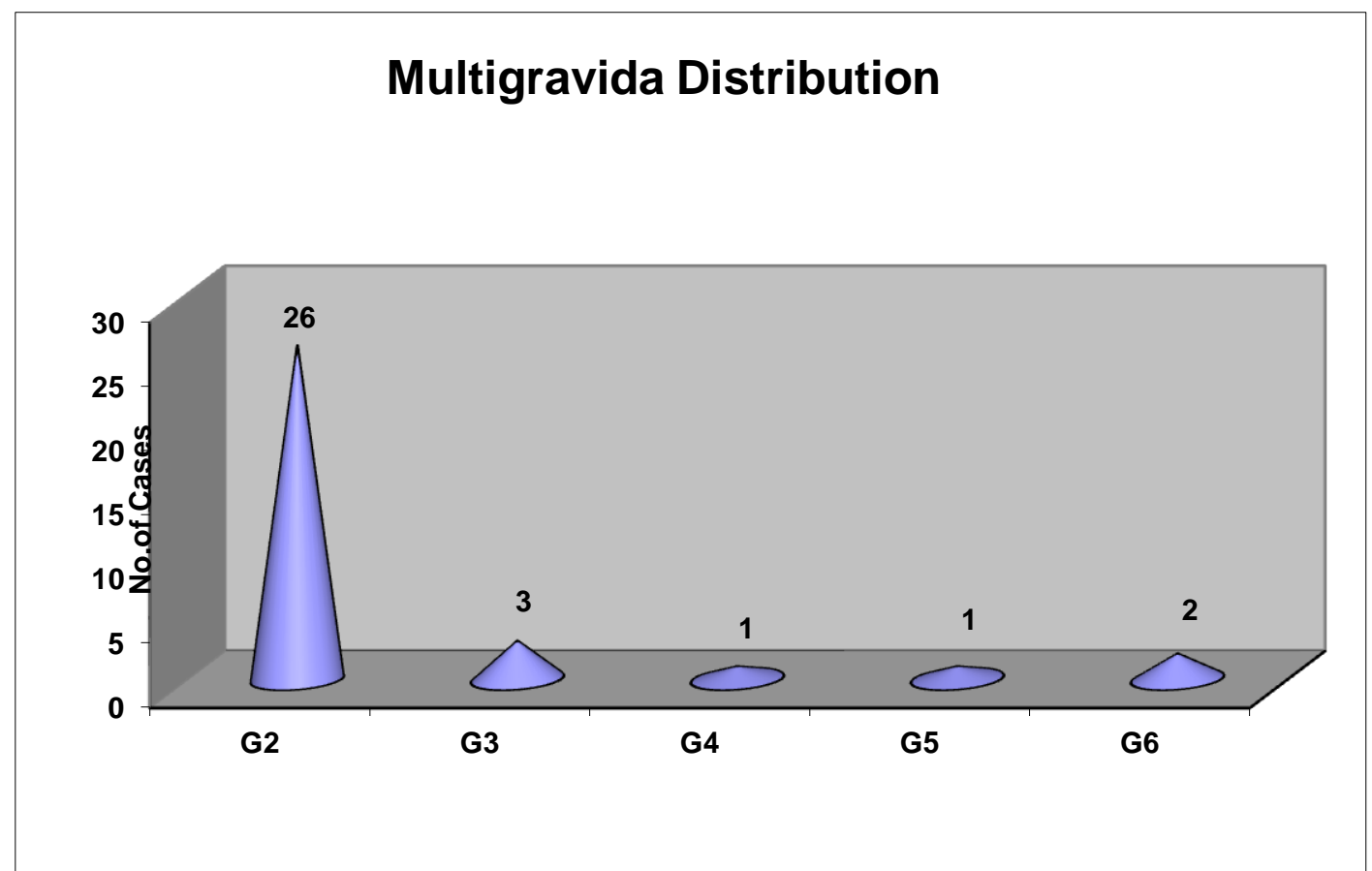

The gravida status of 100 pregnant women in the study ranged from gravida 1 to gravida 6 . Out of 100 pregnant women, $67 \%$ were primigravida and $33 \%$ were multigravida.

\section{THIRD TRIMESTER CORRELATION}

GRAPH NO. 4 A scatter diagram showing the correlation and regression analysis of the TCD with CGA in third trimester. Here TCD is correlated with CGA by $83.9 \%$. 


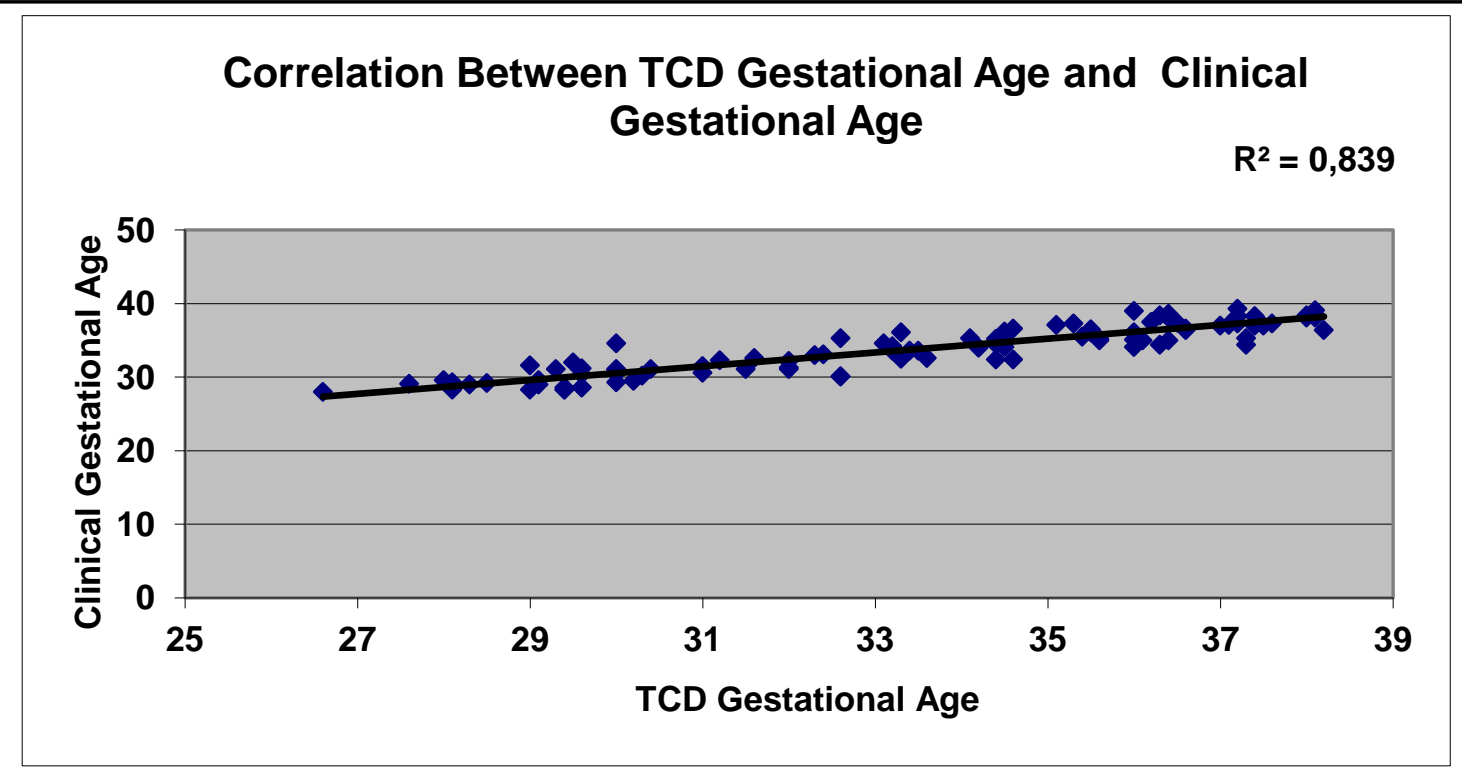

GRAPH NO. 5 A scatter diagram showing the correlation and regression analysis of the TCD with BPD in third trimester. Here TCD is correlated with BPD by $81.7 \%$.

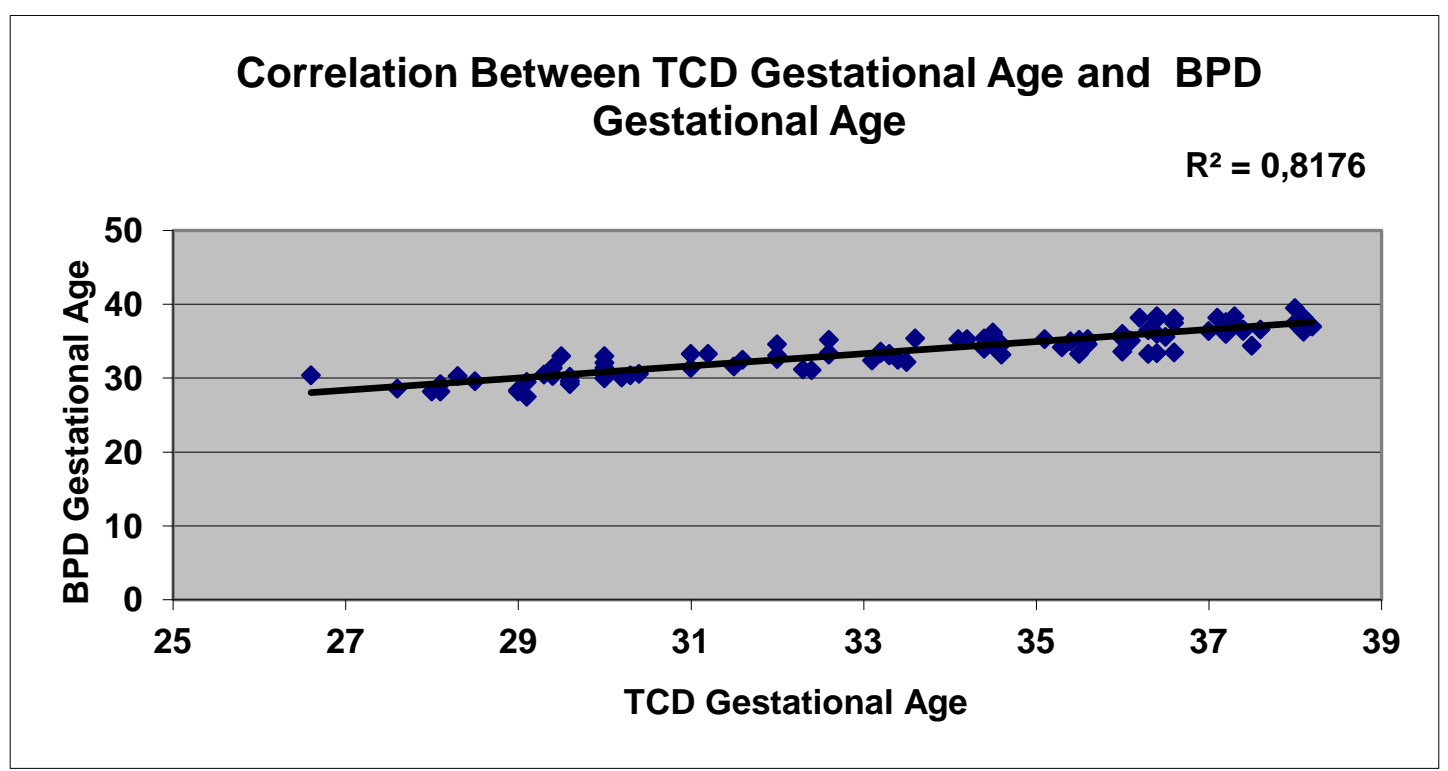

GRAPH NO. 6 A scatter diagram showing the correlation and regression analysis of the TCD with HC in third trimester. Here TCD is correlated with HC by $81.5 \%$.

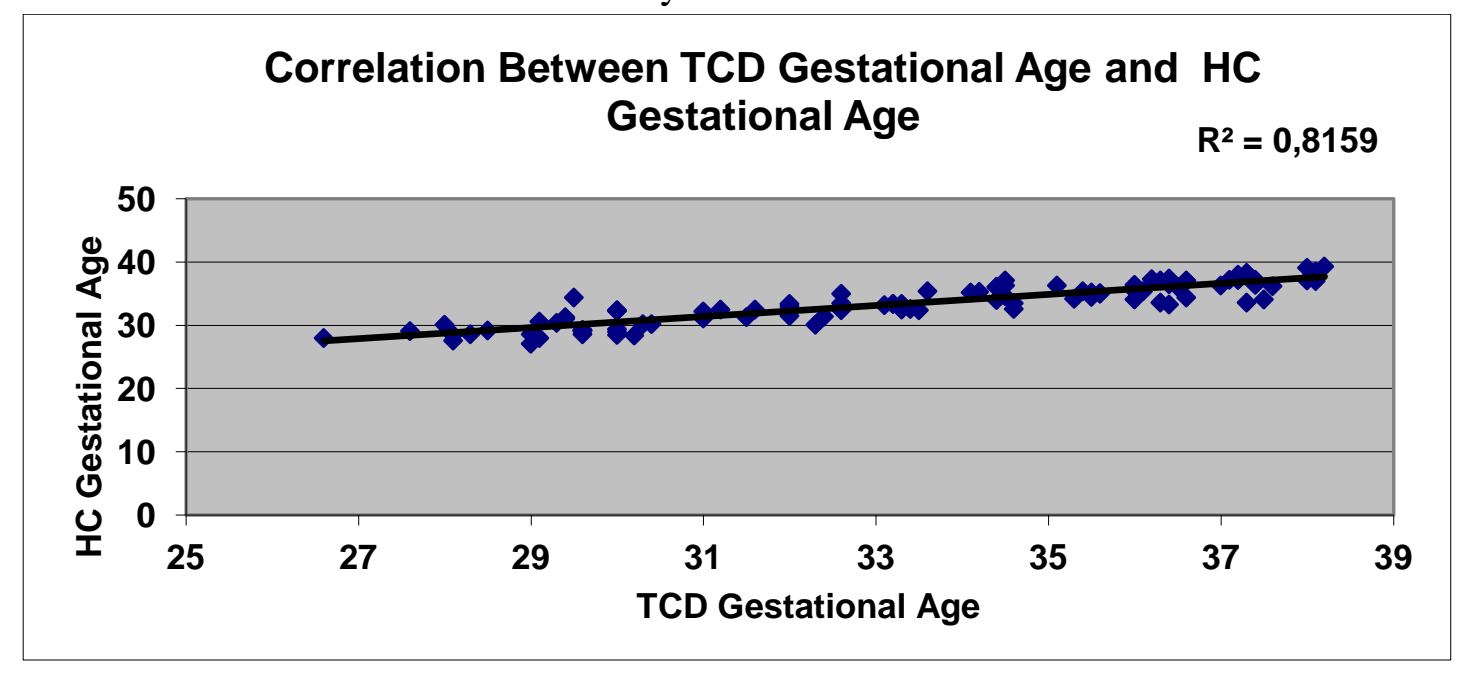




\section{JMSCR Vol||04||Issue||03||Page 9599-9613||March}

GRAPH NO. 7 A scatter diagram showing the correlation and regression analysis of the TCD with AC in third trimester. Here TCD is correlated with AC by $83.2 \%$.

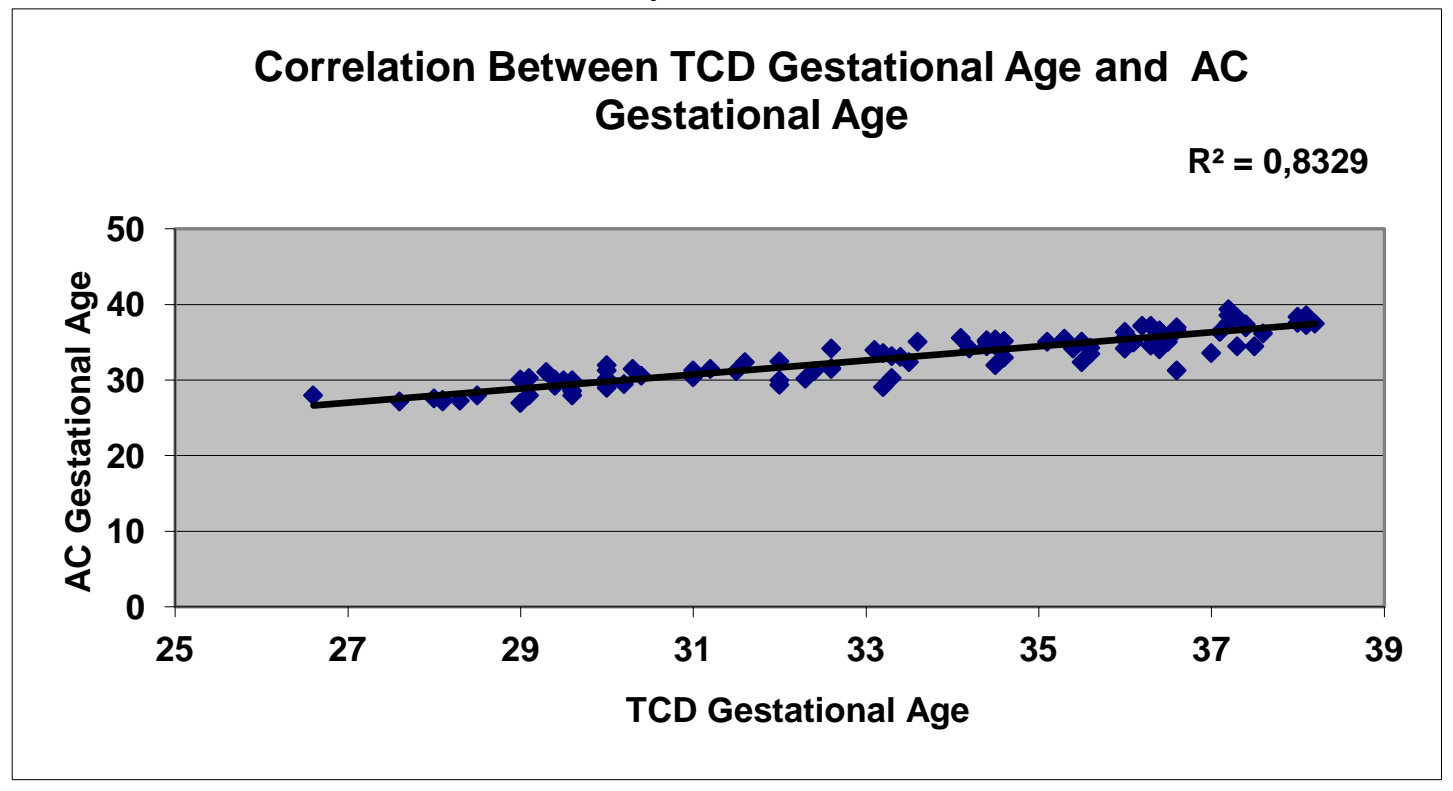

GRAPH NO. 8 A scatter diagram showing the correlation and regression analysis of the TCD with FL in third trimester. Here TCD is correlated with FL by $87.7 \%$.

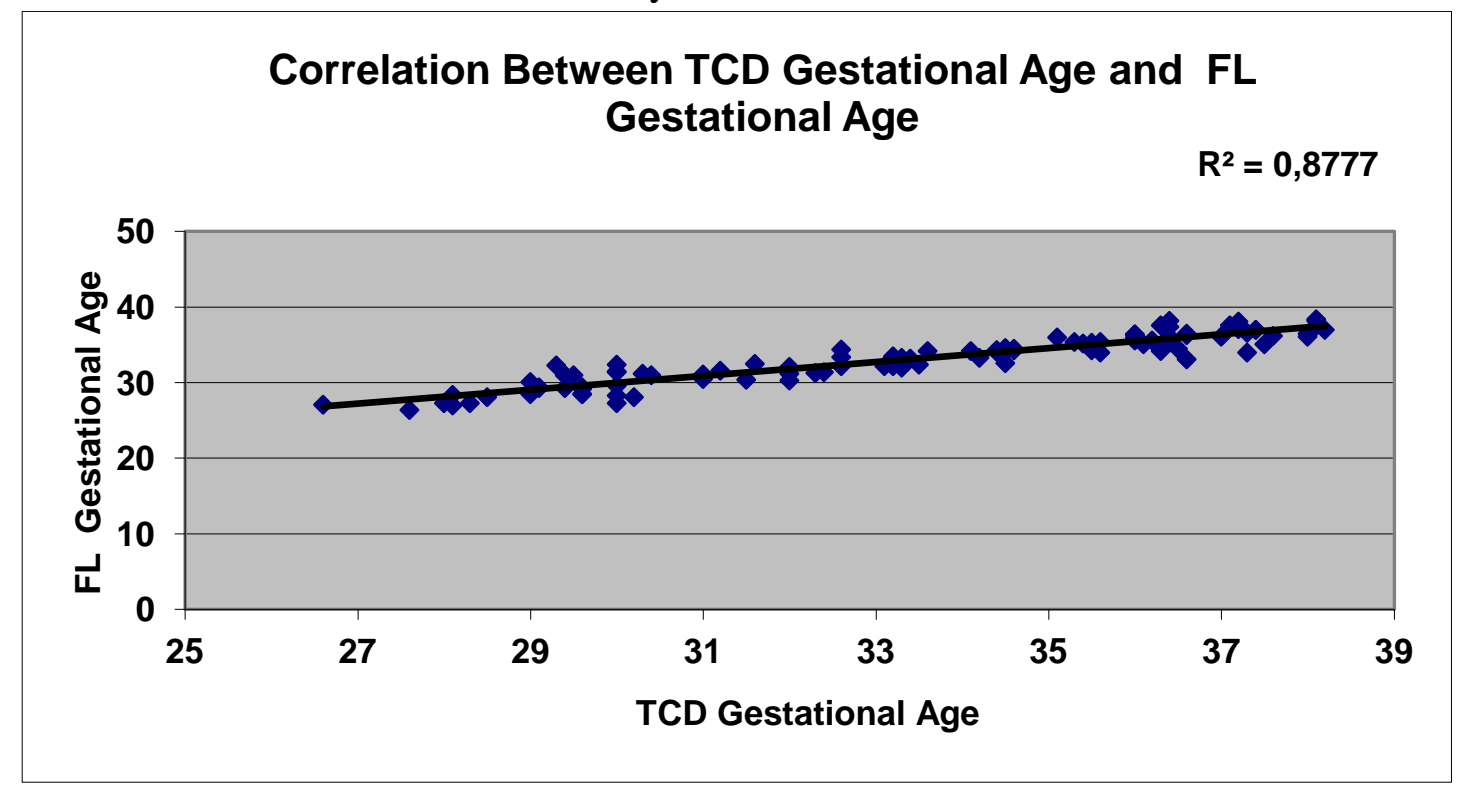

TABLE NO.3 Correlation co-efficient of TCD with CGA, BPD, HC, AC and FL in third trimester:

\begin{tabular}{|l|l|l|}
\hline $\begin{array}{l}\text { Combination } \\
\text { Parameters }\end{array}$ & $\begin{array}{l}\text { Pearson's Correlation } \\
\text { Co-Efficient (r) }\end{array}$ & Significance \\
\hline TCD vs. CGA & 0.916 & $\mathrm{P}<0.001$ \\
\hline TCD vs. BPD & 0.904 & $\mathrm{P}<0.001$ \\
\hline TCD vs. HC & 0.903 & $\mathrm{P}<0.001$ \\
\hline TCD vs. AC & 0.913 & $\mathrm{P}<0.001$ \\
\hline TCD vs. FL & 0.937 & $\mathrm{P}<0.001$ \\
\hline
\end{tabular}

This table reveals the association between the fetal measurements and TCD. The correlation was best for TCD vs. FL ( $r$ : 0.937). The correlation for TCD vs. CGA, BPD, HC and AC was almost similar ( $\mathrm{r}: 0.916$, $0.904,0.903$ and 0.913 respectively). All the correlations were statistically significant. 
TABLE NO. 4 Correlation co-efficient of CGA with BPD, HC, AC, FL and TCD in third trimesters:

\begin{tabular}{|l|l|l|}
\hline Parameters & $\begin{array}{l}\text { Pearson's Correlation Co- } \\
\text { Efficient (r) }\end{array}$ & Significance \\
\hline CGA vs. BPD & 0.849 & $\mathrm{P}<0.001$ \\
\hline CGA vs. HC & 0.872 & $\mathrm{P}<0.001$ \\
\hline CGA vs. AC & 0.890 & $\mathrm{P}<0.001$ \\
\hline CGA vs. FL & 0.913 & $\mathrm{P}<0.001$ \\
\hline CGA vs. TCD & 0.916 & $\mathrm{P}<0.001$ \\
\hline
\end{tabular}

The above table shows the association between fetal measurements with CGA. The correlation was best for CGA vs. FL (r: 0.913) and CGA vs. TCD (r: 0.916). All the correlations were statistically significant.

TABLE NO.5: TCD/AC RATIO:

\begin{tabular}{|l|l|}
\hline TCD / AC Ratio & \\
\hline Mean & 14.924 \\
\hline Standard Deviation & 1.0635 \\
\hline N & 100 \\
\hline
\end{tabular}

$\mathrm{TCD} / \mathrm{AC}$ ratio is 14.924 inthe third trimester with a standard deviation of 1.0635 .

TABLE NO.6 PREDICTED GESTATIONAL AGE FOR TCD OF 31 TO 56 MM:

\begin{tabular}{c|cc|cc|c|}
$\begin{array}{c}\text { Cereb ellum } \\
(\mathbf{m} \mathbf{m})\end{array}$ & $\begin{array}{c}\text { Predicted } \\
\text { Gestational } \\
\text { Age }\end{array}$ & $\begin{array}{c}\text { Std. } \\
\text { Deviation }\end{array}$ & $\begin{array}{c}\text { Cerebellum } \\
(\mathbf{m m})\end{array}$ & $\begin{array}{c}\text { Predicted } \\
\text { Gestational } \\
\text { Age }\end{array}$ & $\begin{array}{c}\text { Std. } \\
\text { Deviation }\end{array}$ \\
\hline 31 & 28.000 & & 44 & 34.650 & 0.9192 \\
\hline 33 & 29.075 & 0.5560 & 45 & 34.667 & 1.3411 \\
\hline 34 & 29.525 & 1.4361 & 46 & 35.367 & 2.5813 \\
35 & 29.575 & 1.0966 & 47 & 35.933 & 1.2097 \\
36 & 30.346 & 1.7845 & 48 & 36.300 & 1.4180 \\
37 & 30.367 & 0.8021 & 49 & 36.333 & 1.9613 \\
38 & 31.050 & 0.6364 & 50 & 36.400 & 2.4791 \\
\hline 39 & 31.700 & 0.8485 & 51 & 37.000 & 0.3742 \\
\hline 40 & 31.967 & 0.7767 & 52 & 37.325 & 2.1140 \\
\hline 41 & 32.320 & 2.2253 & 53 & 37.400 & 1.2302 \\
42 & 32.625 & 1.0658 & 55 & 37.800 & 0.8050 \\
\hline 43 & 33.075 & 0.6076 & 56 & 39.100 & \\
\hline
\end{tabular}




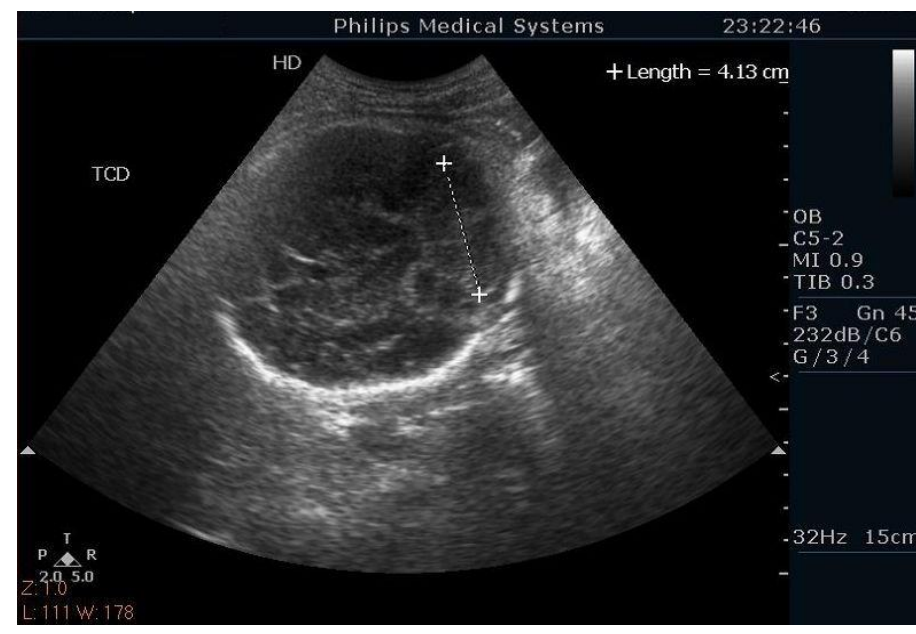

Figure 01 - - Transverse Cerebellar Diameter corresponding to $32 \mathrm{wks}$ 6days gestational age

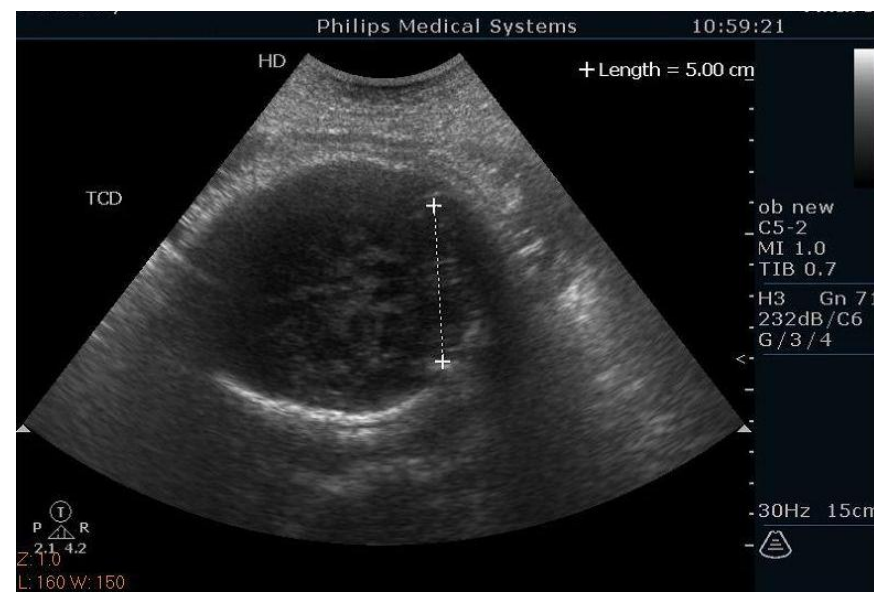

Figure 02 - Transverse Cerebellar Diameter corresponding to 36wks 6days gestational age

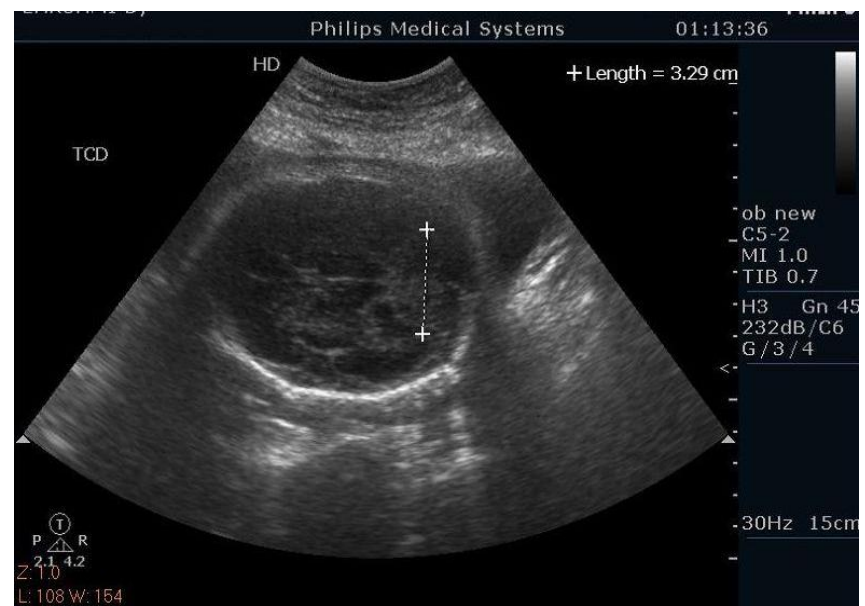

Figure 03- Transverse Cerebellar Diameter corresponding to 28 wks 0days gestational age

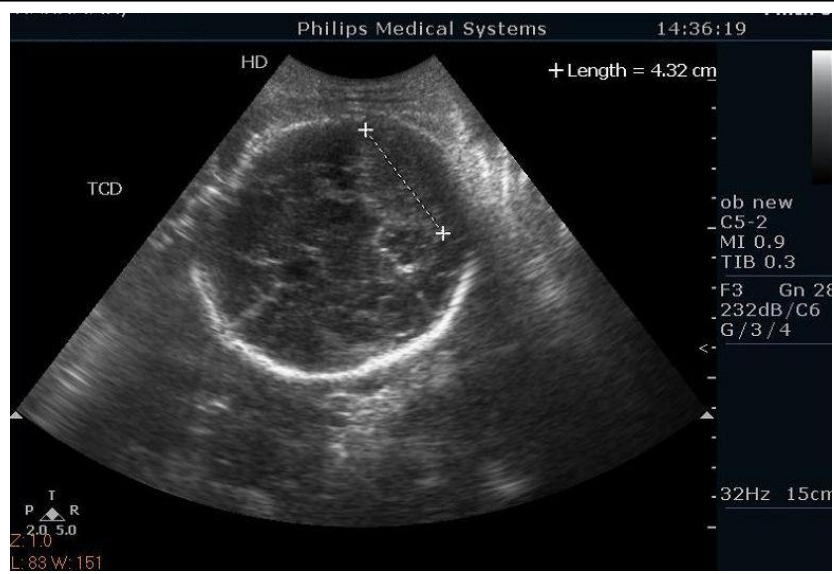

Figure 04- Transverse Cerebellar Diameter corresponding to 33 wks 6 days gestational age

\section{DISCUSSION}

Accurate gestational dating is of paramount importance and the cornerstone for management of pregnancies. Methods to date pregnancies should be simple and straight forward, in all gestational ages. Accurate and easily reproducible sonographic fetal biometric parameters for gestational datingare clinically important for the optimal obstetric management of pregnancies. This is especiallytrue in determining timing of a variety of gestational tests, assessing adequacy of growth and timing of delivery for the optimal obstetric outcome.

In this prospective study of 100 healthy women with uncomplicated pregnancy, a correlation is suggested between the gestational age and TCD. A linear relationship was found during the third (28 wks to term) trimester between the cerebellar growth measured in $\mathrm{mm}$ (millimeters) and the gestational age in weeks. This relationship of fetal cerebellar growth and gestational age is statistically significant.

Many studies have been conducted to assess the variability in gestational age determination from TCD in second and third trimester. In the reported studies $46,31,33,34$ this linear relationship has been established in second and third trimesters correlating well with clinical gestational age. In the present study TCD correlates well with clinical gestational age with high correlation coefficient of 0.916 in the third trimester and also with FL with a high correlation coefficient of 
0.937, as the first accurate parameters for assessing the gestational age. Hence TCD is also one of the significant measurement to be considered.

From a biological perspective, cerebellum is not liable to change in form and size because of dense surrounding petrous ridges and occipital bone. This is at variance with several other biometric parameters, especiallyabdominal circumference, which may be drastically altered by extremes of fetal growth. Hence TCD can be eminently used where it is not possible or difficult to measure BPD or in cases where there are variations in size and shape of fetal head.

TCD has also been measured to predict mean gestational age in different ethnic groups. Fetal TCD is not independent of ethnic origin of patient. Nomogram for TCD can be developed for different countries and races to predict gestational age for a particular ethnic population. In our study, all the patients were of Indian origin and the nomogram for predicting gestational age from TCD was obtained. The values were compared with a study conducted by Hill et. al. ${ }^{47}$ and it was observed that many of the values reported in our study are slightly smaller. This is probably due to the difference in the ethnic origin of patients.

In the study by Neryet. al., the correlation of TCD with BPD, HC, AC and FL were statistically significant with the $\mathrm{P}$ value of $0.92,0.92,0.89$ and 0.90 respectively. ${ }^{42}$ Similarly in the present study the correlation of TCD with other fetal biometric parameters such as BPD, HC, AC and FL were statistically significant with the $\mathrm{P}$ value of 0.904 , $0.903,0.913$ and 0.937 respectively

In the present study, the relationship of fetal TCD to gestational age was considered in normal fetuses only. However, TCD/AC ratio was assessed with an idea of its uses as a parameter for fetal growth abnormalities. The fetal TCD / AC ratio is a gestational age independent method of assessing fetal growth. ${ }^{34-38}$. Malik et al in their study concluded that TCD/AC is constant throughout gestation and was found to be a good tool to diagnose asymmetric IUGR. It was almost $100 \%$ accurate in diagnosing asymmetric IUGR in those cases having TCD/AC ratio exceeding 2SD's. ${ }^{46}$

In normal pregnant women the TCD / AC ratio was fairly constant with the mean of $13.68+/$ 0.96 irrespective of gestational age. ${ }^{34,36,38}$ In the present study the mean TCD/AC was $14.92 \%$ (SD: 1.0635). There was a strong linear relationship between TCD and AC.

TCD/AC ratio was $13.6+/-0.95 \%$ in study done by Campbell et. al. in $1991 .^{38}$ Meyer and his colleagues described that $\mathrm{TCD} / \mathrm{AC}$ ratio is $13.69+/-0.94 \%$ in there study in $1993 .{ }^{35}$ According to studies by Malik et. al. in $2003^{46}$ and $2006^{34}$ TCD/AC ratios were $0.14064+/-0.059$ and 0.13 respectively.

In studies conducted by Malik et. al. ${ }^{46}$ and Meyeret. al., ${ }^{35,36} \mathrm{TCD} / \mathrm{AC}$ ratio greater than the cut off value would be antenatally diagnosed as IUGR. So it was concluded that fetal TCD/AC ratio can be used as an independent method for antenatal diagnosis of IUGR especially in pregnancy with uncertain gestational age.

The results of present study and previously published studies on TCD show that additional small improvements in accurate gestational dating can be achieved by incorporating the results of TCD with some combination of other fetal biometric parameters, including biparietal diameter, head circumference, abdominal circumference, and femur length. Nevertheless, the best combination of biometric measurements remains to be determined. We recommend that TCD be used as an important sonographic biometric parameter for accurate prediction of GA.

\section{CONCLUSION AND SUMMERY:}

TCD positively correlated with BPD, HC, AC and FL.

Nomogram of the TCD shows that there is a linear relationship between the cerebellar growth and gestational age.

TCD/AC ratio was $14.924+/-2$ SD

TCD can be used as a reliable parameter for determination of gestational age in regular obstetric scans. 


\section{SUMMARY:}

Various biometric parameters for gestational age estimation are in vogue. Transverse Cerebellar Diameter is emerging as a new parameter and is claimed to be more accurate in certain situations.

In this study, obstetric sonography was performed in 100 pregnant women with uncomplicated pregnancy to evaluate the efficacy of TCD as a measure to calculate the predicted gestational age. Gestational age ranges from 28 weeks to term. Only patient with known LMP, previous history of normal menstrual cycles and without any exclusion criteria were included in the study. Fetal biometry evaluated includes BPD, HC, AC, FL and TCD.

TCD was correlated with other fetal biometric parameters and clinical gestational age and the correlation was found to be significant. The mean TCD/AC ratio was $14.92 \%$. Nomogram of the TCD shows that there is a linear relationship between the cerebellar growth and the gestational age. So TCD can be used as a reliable parameter for determination of gestational age in mass studies.

To conclude that a parameter value is subnormal or above normal, exact menstrual age should be known, but when it is not known, a menstrual age independent parameter is needed. TCD/AC ratio is one such parameter.

\section{BIBLIOGRAPHY}

1. Peter W. Callen, (1994). Ultrasonography in obstetrics and gynecology, $3^{\text {rd }}$ edition, W. B. Saunders company, Philadelphia.

2. B.Priestly Shan et al, (2010). Revised Estimates of Ultrasonographic Markers for Gestational Age Assessment of Singleton Pregnancies among Indian population.,International Journal of Advanced Science and Technology. Vol 17, April 2010, 1-9.

3. Nyborg, W. L. (2002). Safety of Medical Diagnostic Ultrasound, Seminars in Ultrasound, CT and MRI, 23, 5, 377-386.

4. Mahony, B. S., Callen, P. and Filly, A. R.,(1985). The distal femoral epiphyseal ossification center in the assessment of third trimester menstrual age: sonographic identification and measurement, Radiology, 155, 201-204.

5. Miller, M. W., Brayman, A. A. andAbramowicz, J. S.,(1998). Obstetric ultrasonography: A biophysical consideration of patient safety-the "rules" have changed, Am J ObstetGynecol, 179, 241-254.

6. Noumburg, E., Belloco, R., Cnattigus, S., Hall, P. and Ekbon, A.,(2000). Prenatal ultrasound examination and risk of childhood leukemia: case control study, BMJ, 320, 282-283.

7. Kieler, H., Hagloud, B., Waldenstrom, U. andAxelssson, O.,(1997). Routine ultrasound screening in pregnancy and the children's subsequent growth, vision and hearing, $\mathrm{Br} J$ ObstetGynaecol,104, 12671272.

8. Salaveen, K. A., Vatten, L. J., Eik-Nes, S. H.,Hugdhal, K. andBakketeig, L. S.,(1993). Routine ultrasonography in utero and the subsequent handedness and neurological development, $B M J, 307,6897$, 159-164.

9. Campbell, S. (1968). An improved method of fetal cephalometry by ultrasound, $J$ ObstetGynaecol Brit Cwelth, 75, 568-576.

10. Kurtz, A. B. et. al., (1980). Analysis of biparietal diameter as an accurate indicator of gestational age, $J C U, 8,319-326$.

11. Sabbagha, R. E. and Hughey, M., (1978). Standardization of sonar cephalometry and gestational age. ObstetGynecol, 52, 402406.

12. Hadlock, F. P. et. al., (1982). Fetal biparietal diameter: a critical re-evaluation of the relation to menstrual age using realtime ultrasound, JUM, 1, 97-104.

13. Hadlock, F. P. et. al., (1983). Computer assisted analysis of fetal age in the third trimester using multiple fetal growth parameters, $J U M, 11,313-316$. 
14. Richard D. Mcleary, Lawerence R. Kuhns andMason Barr Jr., (1984). Ultrasonography of the fetal cerebellum, Radiology, 151, 439-442.

15. Hohler, C. W.,(1984). Ultrasound estimation of gestational age. ClinObstetGynaecol, 27, 2, 314-326.

16. Carol M. Rumack, Stephanie R. Wilson and William Charboneau J., (2005). Diagnostic ultrasound, $3^{\text {rd }}$ edition, Elsevier Mosby, Missouri.

17. David Cosgrove, Keith Dewbury and HyltonMeire, (1994). Ultrasound in obstetrics and gynaecology, $1^{\text {st }}$ edition, Churchill Livingstone, Edinburgh.

18. Nyber, D. A. et. al., (1986). Abnormal pregnancy: early diagnosis by US and serum chorionic gonadotropin levels, Radiology, 158, 393.

19. Hellman et. al., (1969). Growth and development of the human fetus prior to the twentieth week of gestation, Am J Obstetgynecol, 103,789.

20. Batzer, F. R et. al., (1983). Landmarks during the first forty-two days of gestation demonstrated by the beta-subunit of human chorionic gonadotropin and ultrasound, Am J Obstetgynecol, 146, 973.

21. Sauerbrei, E., Cooperberg, P. L. and Poland B. J., (1980). Ultrasound demonstration of normal yolk sac, $J$ Clinical Ultrasound, 8, 217.

22. Frank P. Hadlock et. al., (1984). Estimating fetal age: computer assisted analysis of multiple fetal growth parameters, Radiology, 152, 497-501.

23. Doubilet, P. M. and Benson, C. B., (1993). Improved prediction of gestational

24. age in the late third trimester,J Ultrasound Med, 12, 647-653.

25. Jeanty, P. J et. al., (1984). Estimation of gestational age from measurements of

26. fetal long bones, J Ultrasound Med, 3, 7579.

27. Vinkesteijn,A. S. M., Mulder, P. G. H. and Wladimiroff, J. W.,(2000). Fetal transverse cerebellar diameter measurements in normal and reduced fetal growth, Ultrasound in obstetrics and gynecology, $15,1,47-51$.

28. Catherine J. Babcooket. al., (1996). Sonograhic anatomy of the developing cerebellum: normal embryology can resemble pathology, AJR, 166, 427-433.

29. Brayann Bromley et. al., (1994). Closure of the cerebellar vermis: evaluation with second trimester US, Radiology, 193, 761763.

30. Toshiyuki Hata, Atsushi Kuno, Shu-Yan Dai, EisukeInubashiri, Uiko Hanaoka, Kenji Kanenishi, Chizu Yamashiro, Hirokazu Tanaka and Toshihiro Yanagihara (2007). Three Dimensional Sonographic Volume measurement of the fetal Cerebellum. The Japan Society of Ultrasonics in Medicine.Vol 34, No.1, March 2007. 17-21.

31. Mikovic Z. et. al., (1989). Growth of the fetal cerebellum in normal pregnancy, JugoslGinekolPerinatol, 29, 5-6, 157-160.

32. Hata, K. et. al., (1989). Ultrasonographic measurement of the fetal transverse cerebellum in utero, Gynecolobstet invest, 28, 2, 111-112.

33. Goldstein, I., Reece, E. A., Pilu, G., Bovicelli, L. and Hobbins, J. C.,(1987). Cerebellar measurements with ultrasonography in the evaluation of fetal growth and development, Am J Obstetgynecol, 156, 5, 1065-1069.

34. Chavez et. al., (1995). Fetal transcerebellar diameter measurement with particular emphasis in the third trimester: a reliable predictor of gestational age, Am J Obstetgynecol, 191, 3, 979-984.

35. Ghazala Malik, FareesaWaqar, Abdul Ghaffar and Huma Zaidi., (2006). Determination of gestational age by transverse cerebellar diameter in third trimester of pregnancy,JCPSP, 16, 4, 249252. 
36. Meyer, W. J.et. al., (1993). The fetal transverse cerebellar diameter / abdominal circumference ratio: a gestational age independent method of assessing fetal size, J Ultrasound Med, 12, 7, 379-382.

37. Meyer et. al., (1994). Ultrasonographic detection of abnormal fetal growth with the gestational age independent transverse cerebellar diameter / abdominal circumference ratio, Am J Obstetgynecol, 171, 4, 1057-1063.

38. Haller, H., Petrovic, O. and Rukavina B., (1995) Fetal transverse cerebellar diameter I abdominal circumference ratio in assessing fetal size, International journal of gynecology and obstetrics, 50, 2, 159163.

39. Winston A. Campbell et. al., (1991). Transverse cerebellar diameter / abdominal circumference ratio throughout pregnancy: a gestational age - independent method to assess fetal growth, Am J Obstetgynecol, 77, 6, 893-895.

40. Jacquemyn, Y., Sys, SU and Verdonk, P., (2000). Fetal transverse cerebellar diameter in different ethnic groups, $J$ Perinat Med, 28, 1, 14-19

41. Uerpairojkit, B. et. al., (2001). Fetal transverse cerebellar diameter in Thai population groups, J Med Assoc Thai, 84, 1, S346-351.

42. Jose Araujo Holanda - Filho, ArianiImpieri Souza, Alex Sandro Roland Souza, jose Natal Figueroa, Ana Laura Carneiro G. Fereira and Jose Eulalio Cahral-Filho (2010). Fetal Transverse Cerebellar Diameter measured by Ultrasound does not differ between genders. Archives of Gynecology and Obstetrics 2010, August DOI:10.1007/S00404-010-1644-5

43. Goldstein et. al., (1995). Cerebellar growth in normal and growth restricted fetuses of multiple gestation, Am J Obstetgynecol, 173, 4, 1343-1348.
44. Martin R. Chavez et. al., (2007). Fetal transcerebellar diameter measurement for prediction of gestational age at the extremes of fetal growth, J Ultrasound Med,26, 1167-1171.

45. Guan B,(1992).Surveillance of fetal growth and fetal cerebellar transverse diameter by ultrasonographic measurement, Zhonghua Yi XueZa Zhi,72,2, 65-67.

46. Chavez MR, Ananth CV, Kaminsky LM, Smulian JC, Yeo L, Vintzileos AM (2006). Fetal Transcerebellar Diameter measurement for prediction of gestational age in twins, Am J ObstetGynecol2006 Dec ; 195(6):596-600.

47. Hill, L. M., Guzick D. and Fries J.,(1990). Transverse cerebellar diameter as a predictor of menstrual age,ObstetGynecol, 75, 983.

48. Kazamasa Hashimoto, Shimoya, Toru Kanzaki, James F. Clapp and Yuji Murata, (2001). Fetal cerebellum: US appearance with advancing age, Radiology, 221, 7074.

49. Barry B. Goldberg, (2000). Obstetric US imaging : the past 40 years, Radiology, $215,622-629$ 